\title{
FORMAÇÃO CONTINUADA DE DOCENTES DE LÍNGUA INGLESA: CONTRIBUIÇÕES DIDÁTICO-PEDAGÓGICAS DO USO DE AMBIENTES VIRTUAIS DE APRENDIZAGEM
}

\author{
MARSON, Isabel Cristina Vollet ${ }^{1}$ \\ SANTOS, Ademir Valdir dos ${ }^{2}$
}

\begin{abstract}
RESUMO
A pesquisa discute possibilidades formativas da utilização de ambientes virtuais de aprendizagem. Está embasada em atividade de formação com oito professores de Língua Inglesa que atuam no Ensino Superior. As análises estão centradas nas contribuições dos seguintes recursos didático-pedagógicos às práticas educativas: Podcast, Audacity, YouTube, Skypecast, Chat and Webquest. Os dados coletados por meio de perguntas abertas e questionários semiestruturados foram submetidos à análise de conteúdo (BARDIN,1977). Os resultados mostram que os ambientes virtuais de aprendizagem possibilitam gerar práticas educativas com ganhos para 0 ensino-aprendizagem. Foram configuradas categorias relacionadas à formação continuada docente, que exprimem as possibilidades didáticopedagógicas do computador e da Internet: objeto, novo, interação, comunicação, mudança, curso, atualização, Internet, resistência à mudança, melhora, equipamento.
\end{abstract}

Palavras-Chave: Ambientes virtuais de aprendizagem - Docência - Formação continuada Língua Inglesa.

\begin{abstract}
The research discusses the formative possibilities of the virtual learning environment use. It is based on a teaching formation activity with eight English Teachers of college education. The analyses focus on the contribution of the following didactic and pedagogical resources linked to English teaching: Podcast, Audacity, YouTube,Skypecast, Chat and Webquest. The collected data by open questions and semi-structured questionnaires was submittedsubmitted to the content analysis (Bardin, 1977). The results show that virtual learning environments make certain practicespossibles with gains for the teaching and learning process. The analysis presented categories related to teaching development that expresses the didactic-pedagogical possibilities of the computer and the Internet: object, new, interaction, communication, change, course, updating, internet, change resistance, improvement and equipment.
\end{abstract}

KEYWORDS: Virtual learning environment - Teaching - Teacher development - English language.

\footnotetext{
1 Universidade Estadual de Ponta Grossa

2 Universidade Federal de Santa Catarina
} 


\section{INTRODUÇÃO}

No panorama social contemporâneo, a utilização das tecnologias de informação e comunicação, notadamente daquelas que usam a rede mundial de computadores (web) ou internet, indica interferências nos mais variados setores da vida humana, na medida em que são modificadas relações de espaço e tempo, criando novas possibilidades comunicacionais. Essasperspectivas relacionais têm incitado mudanças nos espaços educativos, atingindo as instituições escolares e suas práticas, bem como implicando reflexões sobre o caráter cognitivo pertinente. Assim, seja numa cidade do interior, ou numa metrópole, é possível conectar-se por meio das Tecnologias de Informação e Comunicação (TICs) e de suas ferramentas de acesso, tais como: internet, telefones, TV a cabo, digitais e interativas, telemóveis, smatphones e ipods). Portanto, pode-se interagir, informar-se e mesmo produzir novos conteúdos comunicacionais.Tem-se, contudo, que esse conjunto de informações normalmente é veiculado por uma língua universalmente usada, que é a Língua Inglesa. Imersos neste contexto, atores escolares como professores e alunos estimulados a repensar os instrumentos de ensino e aprendizagem utilizados são, agora, imersos nesse ambiente frenético de geração e trânsito do conhecimento e da informação.

Benefícios pedagógicos e didáticos em relação às possibilidades formativas das tecnologias de informação e comunicação são apresentados aos docentes, como destacam Pretto e Pinto (2006), Porto (2006), Barreto et al (2006), Marson e Santos (2008). Também no que se refere à formação contínua de professores e à introdução de ferramentas tecnológicas na atividade educativa, projetos como o ACOT' (Sandholzet al, 1997) e o ENLACESi'(Acesso, 2002) evidenciam os ganhos positivos gerados para a aprendizagem com a incorporação dos computadores às práticas pedagógicas. Na visão de Beatty (2003, p. 196) os computadores podem ser usados para melhorar o ensino e a aprendizagem e professores e alunos podem caminhar juntos nesta perspectiva de construção cognitiva.

Temos que os debates gerados no campo da pesquisa acabam orientando os dispositivos legais reguladores do campo educativo. Por exemplo, as Diretrizes Curriculares de Língua Estrangeira do Paraná (2008, p. 52-53) salientam que a aula de Inglês deve ser um espaço em que se desenvolvam atividades significativas que explorem diferentes recursos e fontes, para que 0 aluno vincule o que estuda com o que o cerca. A utilização das TICs e de ambientes virtuais de aprendizagem abre as portas para uma série de possibilidades para a atuação docente e, nesse sentido, para a formação de professores.

Em específico, no que se refere ao ensino-aprendizagem de Línguas Estrangeiras, Paiva (2001, p. 114) revela que "O bom professor não é mais o que tudo sabe, mas aquele que sabe promover ambientes que promovem a autonomia do aprendiz e que os desafia a aprender com o(s) outro(s) através de oportunidades de interação e de colaboração". Essa concepção orienta nossa investigação.

O objetivo é apresentar os resultados de pesquisa sobre a formação continuada de professores de Língua Inglesa na Educação Superior e a utilização de ambientes virtuais de aprendizagem e da Internet como elementos didático-pedagógicos capazes de auxiliar a docência e propiciar a aprendizagem. Inicialmente, trazemos aspectos relacionados à necessidade de atualização do professor e uma abordagem de fatores vinculados à formação e à ação docente. Em seguida, detalhamos elementos da metodologia da 
e-Mosaicos - Revista Multidisciplinar de Ensino, Pesquisa, Extensão e Cultura do Instituto de Aplicação Fernando Rodrigues da Silveira (CAp-UERJ)

pesquisa realizada. Na sequência, apresentamos e discutimos os resultados da nossa investigação sobre as contribuições pedagógicas do uso de ambientes virtuais na docência.

\section{SOBRE A FORMAÇÃO CONTINUADA DO DOCENTE}

Se as rápidas transformações do mundo moderno influenciam as relações sociais cotidianas, ocasionam também outra racionalidade para a Educação, implicando tanto uma revisão das formas de ensinar e aprender, como reflexões sobre os diferentes modos de utilização dos espaços escolares. Hoje, o acesso à informação e à comunicação está mais disponível e os indivíduos se comunicam por uma variedade de recursos tecnológicos (Smartphonesiii computadores, internet, televisão, tablets ${ }^{j}$ ). A difusão das tecnologias de informação e comunicação (TICs) na sociedade produz impactos nos variados setores e oportuniza o contato com outros sujeitos em qualquer ponto do planeta. $\mathrm{O}$ ato de educar, neste contexto social e cultural, não se limita ao domínio de conteúdos e técnicas, como preconizava a abordagem tradicional, mas reposiciona as conexões dos sujeitos com o tempo e o espaço. Segundo Kenski (2006, p. 29), a inserção rápida da informatização nos espaços escolares gera configurações espaciais, temporais e de aprendizagem antes não previstas. Mas na concepção de Masetto (2006, p. 134-136) ainda existe resistência dos professores à utilização das TICs nos espaços escolares. Deriva que o seu uso na docência, motivando o processo ensino-aprendizagem, ainda não é uma prática em elaboração, uma vez que parte dos professores resiste ao uso formal, com finalidade didática, das TICs no fazer pedagógico. Moerschel (2009, apud KHALIL, 2013) aponta várias razões para a resistência dos professores à tecnologia, incluindo limitada visão de futuro, tendência a manter as coisas como elas estão, percepção da formação deficitária em relação à informação e comunicação e a crença de que eles não têm as habilidades para lidar com a tecnologia. Para Bohn (2006, p. 128), "[...] a inovação exige por parte do professor uma atitude de contínua aprendência. $O$ novo só pode florescer se a mente estiver isenta de crenças, ideologias, dogmas restritivos". E ainda no que se refere à acessibilidade dos recursos provindos da internet, Campos et al. (2003, p. 46) destacam que a internet tem se tornado bastante popular e possibilitado que aprendizagens outras ocorram fora dos limites da sala de aula, ultrapassem os "muros" da escola, estimulando a criação de ambientes virtuais de aprendizagem e a aprendizagem cooperativa.

$\mathrm{Na}$ nossa concepção, é necessário discutir a natureza dos usos de tecnologias como o computador e a Internet na Educação, mas com a condição de superação da racionalidade técnica e instrumental, pois as tecnologias de informação e comunicação podem ser inseridas no espaço escolar como elementos pedagógicos promotores de aprendizagem e autonomia. (BRITO e PURIFICAÇÃO, 2006, p. 31-32).

Especificamente para o professor de língua inglesa, as TICs estão relacionadas à expansão das formas de comunicação no mundo globalizado, visto que há uma grande gama de informações em inglês na Internet. Também por isso, é imprescindível que este profissional esteja atento às potencialidades educativas nesse ambiente tecnológico, pois ignorá-las pode significar "obsolescência pedagógica" (Souza, 2000).

Tal perspectiva formativa é vislumbrada ainda no projeto de diretrizes estratégicas para a Ciência, Tecnologia e Inovação e destaca que um dos objetivos da educação é preparar os cidadãos para 
a carreira técnico-científica, de modo que possam atuar de maneira crítica no mundo globalizado (MELO; SILVA, 2001). Alinhadas aos debates que buscamos nutrir, considerando o papel das tecnologias educacionais na formação, as pesquisas desenvolvidas por Warschaueret al (2003), Wang (2005) e Paiva (2001) demonstram ganhos pedagógicos na docência da Língua Inglesa, com a utilização do computador e da Internet no meio escolar. Já Weasenforth (2001) ressalta que a Internet pode ser utilizada para três fins: educativo (ensino), crescimento acadêmico (pesquisa) e profissional (autodesenvolvimento). Ou seja, ela se constitui num instrumento pedagógico eficiente, se empregado como estimulador da pesquisa, do desenvolvimento de trabalhos colaborativos e da autonomia dos sujeitos aprendentes. Sob o mesmo ponto de vista, Campos et al (2003, p. 46) destacam que o uso das TICs pode ampliar ou melhorar ambientes onde as situações acontecem e o uso das suas ferramentas possibilita o engajamento dos indivíduos e a produção de conhecimento compartilhado. Para Kenski (2006, p.74), o uso didático das TICs se torna contributivo se associado a mudanças nas posturas docentes e discentes e na alteração dos tradicionais papéis de cada um desses agentes na sala de aula.Nessa mesma perspectiva, Schön (1988) sugere a noção de "aprender na prática"; em seus termos, o professor pode modificar a docência através de novas maneiras de ensinar e aprender, rejeitando as velhas práticas e substituindo-as por outras inovadoras.

\section{Metodologia dA PESQUisA}

Considerada a relação entre a formação docente continuada e a utilização das TICs, mais especificamente o uso do computador e da Internet, realizamos uma investigação, embasada num curso de formação com professores de Língua Inglesa de uma instituição de ensino superior, focando a utilização de ambientes virtuais de aprendizagem.

Tal curso teve duração de 30 horas, distribuídas num cronograma com abrangência de seis semanas, com atividades presenciais e a distânciav. Os encontros presenciais aconteceram aos sábados, num laboratório de informática, de modo que estivessem à disposição os recursos tecnológicos necessários às práticas formativas planejadas. Como se tratou de trabalho com docentes com proficiência em inglês, as comunicações orais e escritas do curso foram feitas com o uso do idioma estrangeiro, exclusivamente. Participou um grupo de oito professores de disciplinas de Língua Inglesa, assim caracterizado: sete deles são licenciados em Letras e um é formado em Direito; o tempo de atuação docente varia entre sete e 21 anos; todos já tinham feito algum curso básico de informática, estando aptos a lidar com as ferramentas e aplicativos disponibilizados. Os trabalhos foram realizados em pares, com a intervenção dos pesquisadores nos momentos de planejamento, execução, apresentação e avaliação das atividades formativas. Após cada encontro presencial, os professores recebiam tarefas que deveriam ser cumpridas no período de tempo que decorreria até 0 próximo encontro, constituindo assim as atividades a distância.

Considerando o objetivo de discutir as possibilidades pedagógicas da utilização de computadores em rede e da Internet na docência, foi identificado um conjunto de recursos de base tecnológica aplicável a atividades educativas, disponibilizados para utilização e avaliação dos professores universitários de língua inglesa no curso de formação: Podcast, Audacity, YouTube, Skypecast ${ }^{\prime i}$, Chat e Webquest.

Duas atividades contemplaram experiências pedagógicas com áudio: Podcast e Audacity. O Podcasté uma 
e-Mosaicos - Revista Multidisciplinar de Ensino, Pesquisa, Extensão e Cultura do Instituto de Aplicação Fernando Rodrigues da Silveira (CAp-UERJ)

possibilidade de disponibilizar áudio pela Internet, sendo que o usuário assina gratuitamente canais disponibilizados e recebe os arquivos periodicamente. Já o Audacity é um editor que permite captar e editar sons. O uso pedagógico sugerido aos professores foi uma gravação e reprodução de áudio e sua disponibilização para os outros participantes do curso. Essa prática é algo inovador, visto que, na maioria das vezes, os professores já trazem o áudio pronto para as aulas de Língua Inglesa. O que se preconiza é a elaboração de gravações, considerando as características dos alunos e o seu estágio de aprendizagem do idioma, mobilizando outras formas de aprender, tanto por parte do docente como pelos discentes. Neste caso, pode-se criar uma série de exercícios com uso da língua em tempo real, acrescentando elementos que despertem a curiosidade e criatividade. Os arquivos de áudio disponibilizados na Internet têm qualidade no que se refere à pronúncia, ao conteúdo e atualidade dos tópicos, o que é importante de se observar quanto às possibilidades didáticas em tela. Por meio da instalação do software Audacity, o professor pode fazer a edição de áudio conforme os objetivos de aprendizagem. Por exemplo, é viável criar um programa de rádio, cujo conteúdo esteja também atrelado às finalidades formativas do ensino.

Acessível na Internet, a seleção e utilização de vídeos disponibilizados no YouTube, que é um site que compartilha vídeos pela Internet, acrescenta às potencialidades de áudio os recursos imagéticos em movimento. Estamos hoje num momento em que o acesso ao YouTube está bastante difundido. Cabenos, todavia, discutir suas possibilidades para a formação docente. Os professores verificavam a possibilidade de utilizar os vídeos na complementação das aulas presenciais, considerando o uso da Língua Inglesa em função dos objetivos de aprendizagem pretendidos. Aqui importa, principalmente, a seleção criteriosa de vídeos com potencial didático-pedagógico que atenderá às finalidades educativas. vii

O ensino e a aprendizagem de um idioma estrangeiro estão diretamente vinculados ao domínio das habilidades de construção de comunicação entre os sujeitos, quanto à fala, à compreensão na escuta e à escrita. De modo a avaliar o potencial didático de atividade docente com recurso tecnológico enfatizando a oralidade, outra ação realizada no curso foi a constituição de comunidades de aprendizagem com o uso de Skypecast, (hoje tratado simplesmente como Skype) que é uma sala virtual em áudio funcionando em tempo real, possibilitando que várias pessoas se comuniquem, estando em lugares distintos. A atividade proposta permitiu que os professores se comunicassem com outros falantes de Língua Inglesa, todos postos em contato pela Internet. Cabe lembrar que a criação de salas virtuais online via Skypecast requer a instalação do programa Skype nos computadores, que o usuário se cadastre e crie sua própria sala virtual, para onde chamará os participantes discentes. Há possibilidades de uso na escola pública ou em quaisquer instituições com carência de recursos. A comunicação, que é orientada pelo docente nestas salas virtuais, é feita em tempo real, estimulando a aprendizagem embasada no falar e escutar o idioma ${ }^{\text {viii. }}$ Com mesmo objetivo, as atividades com o chat $^{\text {ix }}$ permitiram a comunicação em tempo real. Também nesse momento, houve preocupação de vincular a um currículo, incluindo alguns tópicos relevantes dos conteúdos que surgiram no momento da aula, também com ênfase na oralidade. Na utilização de chats, cabe a descoberta de endereços eletrônicos apropriados onde os alunos serão estimulados a exercitar as conversações, desenvolvendo habilidades linguísticas e a 
interação. Nesse sentido, é viável indicar que as possibilidades são quase incontáveis, dada a expansão atual das redes comunicacionais.

A criação de material didático disponibilizado pela internet também foi uma atividade proposta aos docentes para a qual se utilizou a ferramenta de incentivo à pesquisa denominada Webquest, baseada na aprendizagem colaborativa e na construção do conhecimento. Essa metodologia possibilita o engajamento de professor e alunos no uso da Internet, estimulando a pesquisa e 0 pensamento crítico. 0 coordenador da atividade pode sugerir os temas de pesquisa, tendo o cuidado de disponibilizar endereços eletrônicos previamente selecionados onde se trata do assunto, de modo a orientar a investigação e os estudos de modo que se ampliem as possibilidades de atingir os objetivos de aprendizagem do idioma, observado e diagnosticado o estágio de compreensão linguística dos alunos. $\mathrm{Na}$ construção online das Webquests, podem ser utilizadas ferramentas do ambiente virtual que permitem o uso de cores, imagens e fontes diversificadas, o que amplia o universo didático de sua exploração. Na sua elaboração, há a etapa de introdução convidando à pesquisa; depois são discriminadas as tarefas que podem ser debates, discussões, criação de um cartaz de propaganda, promoção de um evento, apresentação oral; na etapa de processo são mostrados os passos a seguir para desenvolver a tarefa $\mathrm{e}$ sugestões de links para auxiliar a investigação; na avaliação se detalha como os alunos serão avaliados e há a possibilidade de utilizar um sistema de rubricas ${ }^{x}$ inserindo os parâmetros com que se avaliará a atividade criada; na conclusão, o assunto que foi exposto na introdução é retomado e se estimula à continuidade da investigação pelos aprendentes.
Outrossim, também foram identificados endereços online que permitem a construção de material didático para aplicação nas aulas. Foram discutidas as possibilidades pedagógicas de exercícios de leitura, escrita e audição, jogos, fóruns de discussão e outras atividades propostas pela ludicidade, fóruns de discussão e outras atividades disponíveis em websites ${ }^{k i}$.

As atividades a distância se destinaram à finalização das atividades didático-pedagógicas trabalhadas nos encontros presenciais, uma vez que o acesso e exploração dos ambientes virtuais e de outros endereços indicados exige várias horas de dedicação. Cada docente em formação, de acordo com características como o estágio de sua alfabetização tecnológicaxiie de criação de hábitos e domínio das ferramentas de informática em discussão, avançava no processo de acordo com seu ritmo próprio. O período não-presencial se destinou, também, à discussão e avaliação do que era proposto no curso a cada encontro presencial.

A avaliação do processo foi realizada nas etapas presenciais, para cada uma das atividades propostas aos professores. Estes respondiam e debatiam sobre as perguntas deixadas no fórum de discussão ${ }^{\text {xiii }}$ e nos questionários referentes às atividades trabalhadas. As perguntas foram pautadas por elementos centrais no processo de ensino-aprendizagem e nas características particulares vinculadas ao ensino-aprendizagem idiomático. Os depoimentos docentes registrados nos questionários e no fórum de discussão do ambiente virtual de aprendizagem foram submetidos à análise de conteúdo, metodologia conforme aos estudos de Bardin (1977).

A análise de conteúdo de Bardin (1977, p. 89) se divide em três fases: "a pré-análise, a exploração do material e 0 tratamento dos resultados, a inferência e a 
interpretação". Na primeira fase, houve a exploração do material, sistematização das ideias e formulação das hipóteses. $\mathrm{Na}$ segunda fase, realizamos a escolha dos documentos e seleção das unidades de análise. $\mathrm{Na}$ última fase, tabulamos e verificamos a frequência de ocorrência das palavras-chave no conjunto de respostas registradas nos documentos. Verificamos os termos relacionados ao uso de tecnologias de informação e comunicação, em especial a Internet na prática do professor de Língua Inglesa.

\section{A UTILIZAÇÃO DE AMBIENTES VIRTUAIS NA DOCÊNCIA E FORMAÇÃO DO PROFESSOR: AVALIANDO CONEXÕES E POSSIBILIDADES}

As atividades desenvolvidas no curso de formação continuada tinham como prioridade a construção do conhecimento de modo interativo e dialógico, engendrando aprendizagens individuais e coletivas aplicáveis à docência daqueles professores de Língua Inglesa, com ganhos didático-pedagógicos que viessem a contribuir positivamente na elaboração de suas aulas. As possibilidades tecnológicas da Internet deveriam estar a serviço da promoção de aprendizagens dos alunos, incentivando uma postura autônoma e criativa diante do conhecimento disponibilizado.

Já no primeiro encontro, os professores demonstraram interesse em aprender outras formas de ensinar que incorporassem as inovações tecnológicas e destacaram que a formação contínua é um aspecto essencial para o desenvolvimento do professor. Nas suas falas:

- Eu estou disposta a rever minha prática e estar trabalhando

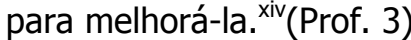

- Eu tenho o forte desejo de aprender novas práticas, melhorar minhas aulas e fazer as coisas acontecerem. (Prof. 5)
- Nós temos que ter cabeças abertas [...] e tentar descobrir 0 que os nossos alunos realmente querem e tentar melhorar seu conhecimento. Eu não tenho utilizado muitos recursos tecnológicos, mas gostaria de inovar minhas aulas... e estou pronta para aprender a fazer isso.(Prof. 8)

Esse aspecto chama atenção para a necessidade de superação das eventuais resistências que os professores possam apresentar quanto ao uso de tecnologias na prática educativa. Porém, alguns professores ressaltaram que as oportunidades de formação e de atuação, que incluem a introdução das TICs na educação, ainda são restritas e são limitadas pelos recursos existentes, quer nas instituições de formação docente, como nas escolas onde se queira colocar em prática as atividades. Percebemos assim que projetos dessa natureza podem ter êxito se forem incluídos nas políticas educacionais, dependendo também de apoio administrativo.

Quando os docentes trabalharam com a metodologia denominada Webquest, que incentiva 0 aluno à pesquisa, se observou que é possível fazer conexões entre a Língua Inglesa e outras disciplinas dos cursos de graduação, para que se atente às aplicações da língua nos diversos contextos da realidade profissional e humana. Uma das equipes demonstrou um modelo de Webquest aplicado à área da Enfermagem denominado FirstAid procedures withburns, em que os alunos deveriam procurar os tipos e formas de tratamento para queimaduras de primeiro, segundo e terceiro graus (Fig. 1). Nesse caso, os estudantes poderiam relacionar o que aprenderam nas aulas específicas de orientação clínico-médica e estabelecer 
e-Mosaicos - Revista Multidisciplinar de Ensino, Pesquisa, Extensão e Cultura do Instituto de Aplicação Fernando Rodrigues da Silveira (CAp-UERJ)

comparações com o conhecimento apresentado em Língua Inglesa.

A percepção dos docentes em curso sobre as potencialidades pedagógicas das Webquests é exemplificada pela seguinte avaliação:

- Gostei muito desta metodologia de incentivo à pesquisa denominada Webquest, pois eu já queria fazer algo nesse sentido. Nas avaliações que os alunos fazem da minha disciplina (Comissão Própria de Avaliação), eu sempre tinha uma pontuação baixa no quesito "pesquisa". Essa é uma maneira dinâmica de fazêlos pesquisar em Língua Inglesa..." (Prof. 3)

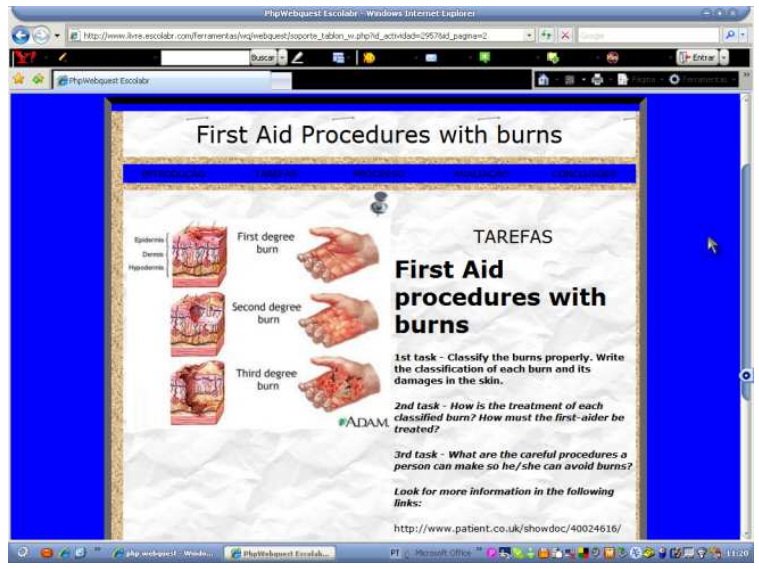

Figura 1 - Webqueste aplicações didáticas criadas pelos professores

$\mathrm{Na}$ avaliação, foi evidenciado que a geração das Webquests é trabalhosa, pois o docente necessita ter amplo conhecimento do assunto proposto na pesquisa e tempo para a preparação das atividades. E elas foram avaliadas como positivas, pois têm a possibilidade de encantar os alunos com a disposição de textos e cores, bem como estimular a criatividade e a autonomia. Ratificamos, diante destes resultados, a importância do professor fazer conexões entre sua disciplina e as demais componentes curriculares, como destaca Morin (apudCelani, 2006, p. 37) "[...] o professor não pode, como é ainda comum, perceber o objeto de sua disciplina como algo autosuficiente, sem fazer ligações com outros objetos estudados em outras disciplinas, ligações com o universo de que ele e seu aluno fazem parte".

No encontro de formação docente em que trabalhamos a constituição das comunidades virtuais de aprendizagem através do Skypecast, pudemos perceber que as atividades de comunicação podem ser determinadas pelo número de participantes na sala. Ou seja, quanto menores os grupos, ampliam-se possibilidades de exploração didática dos usos da língua. De fato, a utilização desse recurso implica a constituição de uma comunidade de aprendizagem, unida em torno do objetivo de aprender. De acordo com Harasim (2005, p. 21), comunidades de aprendizagem são "grupos de pessoas que utilizam as redes de comunicação mediadas pelo computador para aprender juntas, no horário, no local e no ritmo mais adequados para elas mesmas e para a tarefa em questão". Sobre o uso de salas virtuais online para comunicação via Skypecast, um dos docentes avaliou:

- Eu gostei tanto da sala virtual
que já pedi para os meus alunos
particulares baixarem o programa
Skype e eu estou planejando ter
reuniões frequentes com todos
eles. No princípio eles ficaram
assustados, 'Mas eu vou ter que
falar com pessoas que não
conheço?'; 'Eles irão rir de mim e
do meu inglês?' (palavras deles),
mas eles disseram que vão
participar. Será um pouco
diferente porque nós falaremos e
eles usarão suas habilidades, eles
ficarão envergonhados, mas ao
mesmo tempo será um desafio,
um bom desafio. (Prof. 4)

- Eu gostei tanto da sala virtual que já pedi para os meus alunos particulares baixarem o programa Skype e eu estou planejando ter reuniões frequentes com todos (aram assustados, 'Mas eu vou ter que falar com pessoas que não conheço?'; 'Eles irão rir de mim e do meu inglês?' (palavras deles), mas eles disseram que vão participar. Será um pouco diferente porque nós falaremos e eles usarão suas habilidades, eles ficarão envergonhados, mas ao um bom desafio. (Prof. 4) 
e-Mosaicos - Revista Multidisciplinar de Ensino, Pesquisa, Extensão e Cultura do Instituto de Aplicação Fernando Rodrigues da Silveira (CAp-UERJ)

Considerada a importância do domínio da oralidade para o ensino e aprendizagem de uma língua estrangeira, as atividades com Podcast, Audacity, YouTubee Chat foram avaliadas diante de uma pergunta deixada no fórum de discussão: Whatimpact these audio tools can provoke in your classes? ${ }^{x v} U m$ dos docentes em formação respondeu:

- Nesta atividade foi necessário usar tecnologia (Internet), um bom domínio do Inglês, imaginação e criatividade. Os alunos e os professores devem estar dispostos a interagir neste exercício. Isso consome tempo e dedicação para concluir a atividade, mas é muito compensador porque ela é muito interessante e atraente para ambos, o aluno e o professor. Eles devem trabalhar juntos compartilhando idéias e informações necessárias para que haja resultados satisfatórios. [...] Nossas aulas se tornam vivas, interessantes e significativas com essas ferramentas. (Prof. 2)

Tais resultados indicam que a introdução de recursos tecnológicos no contexto escolar possibilita o redimensionamento de práticas, solicita o comprometimento de professores e alunos. Lembramos, ainda, que requer também o apoio institucional para que se efetive. Hutmacher (apud Almeida, 2000, p. 123) ressalta que "as novas práticas são inventadas, conquistadas, construídas coletivamente, e não no isolamento individual". Ou seja, partilha e cooperação são valores incentivados.

Mas a metodologia da pesquisa previu não somente a proposição e discussão de atividades para os docentes de Língua Inglesa, com a incorporação de práticas com o computador e a Internet, mas também a coleta e análise dos dados sobre as possibilidades formativas que foram registradas pelos professores participantes nos questionários e nos depoimentos do fórum de discussão do ambiente virtual de aprendizagem. Como já foi explicitado, a análise de conteúdo foi aplicada ao teor das mensagens docentes registradas. Isto permitiu o encontro de onze categorias relacionadas à formação continuada: objeto, novo, interação, comunicação, mudança, curso, atualização, Internet, resistência à mudança, melhora, equipamento.

A categoria "objeto" está relacionada ao modo como os docentes percebem as atividades como dependentes dos recursos didático-pedagógicos materiais. As respostas da maioria dos professores denotam a mera utilização de recursos tecnológicos - computador, multimídia, DVD, CD - como meio de corporificar uma atividade educativa. Essa é uma questão essencial para a discussão das práticas pedagógicas com as tecnologias educacionais disponíveis, que deve levar à superação dessa racionalidade técnicoinstrumental. A segunda categoria que emergiu da análise categorial foi "novo". Para os respondentes, os recursos midiáticos $^{\mathrm{xvi}}$ são considerados inovadores. $\mathrm{Na}$ concepção da maioria, computadores, multimídia, televisão, DVD, CD, Smartphones, tablets - são considerados inovações. Ou seja, equivocadamente, a inovação na prática pedagógica estaria subordinada à utilização dos meios. Eis um estágio a ser superado nas práticas de formação de professores.

Notamos que a ideia ou representação da maioria dos docentes a respeito da constituição de comunidades de aprendizagem é positiva. Para eles, o conceito de comunidade virtual de aprendizagem gravita em torno das categorias "interação" e "comunicação"xvii". Consideramos que no ensinoaprendizagem da Língua Inglesa, essas categorias são essenciais à docência. A 
fala e o uso da língua em situações reais são condições para a aprendizagem.

$\mathrm{Na}$ interpretação das respostas inseridas no fórum de discussão relacionadas ao "tipo de professor" e à "busca de atualização" percebemos uma bipolarização entre o docente conservador (ou tradicional) e àquele propenso às mudanças. Dois professores não responderam aessa questão e quatro afirmaram que a Internet é um meio útil para a atualização. Nesse contexto, surgiram as categorias "mudança" e "curso". No que se refere à renovação da prática, ressaltaram que os meios de sua atualização estão diretamente relacionados à participação em cursos acadêmicos. Ratificamos que a formação do professor é um processo contínuo. 0 desenvolvimento profissional se constitui através da percepção que o educar não é estático e que a docência é alicerçada na pesquisa, ação e revisão da prática (Pimenta; Anastasiou, 2002, p. 89). A categoria "mudança "emergiu nos registros do fórum e reflete uma vontade de transformar a prática educativa diretamente relacionada à superação e vontade de vencer medos e dificuldades em relação ao uso das TICs. A categoria "melhora" surgiu nos documentos que trataram da reflexão sobre a prática com utilização de recursos tecnológicos como a Internet, com base em respostas frequentes como "mudanças que visem o melhor" (Prof. 1), "estou com vontade de mudar, de melhorar" (Prof. 2), "aprender novas práticas, melhorar minhas aulas" (Prof. 5).

Ainda se referindo ao tema da atualização e da prática docente criativa, a categoria "Internet" emergiu na leitura flutuante dos depoimentos registrados no

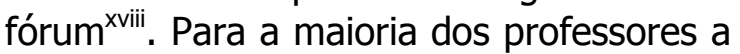
"Internet" é considerada um meio eficiente de atualização e busca, de interação e de troca de experiências. A experiência de utilização da Internet e de ambientes virtuais como ferramenta na docência da Língua Inglesa se mostrou positiva e promissora sob a perspectiva formativa que abriga. Os professores salientaram a importância de terem ao seu alcance processos e recursos formativos para aplicação didático-pedagógica das tecnologias, embora essa condição ainda seja um tanto quanto restrita.

Ratificamos que a implantação de projetos pedagógicos que envolvam tecnologias no campo educacional deve prever a contínua atualização da formação docente e investimentos em relação ao espaço físico e equipamentos, uma vez que os avanços na base materialtecnológica disponível e também nas discussões quanto aos aspectos cognitivos se renova com extrema rapidez. As tecnologias de informação e comunicação, especialmente os computadores e a Internet - onde se alojam os ambientes virtuais, auxiliam na elaboração de práticas pedagógicas em consonância com o atual estágio de desenvolvimento científico, criando novas possibilidades para o ensino-aprendizagem no panorama educativo escolar. Todavia, entendemos que é necessário ressaltar que seu uso na escola brasileira está vinculado à superação de desigualdades sociais que ainda limitam o acesso aos recursos tecnológicos tanto dos professores como dos alunos. Nesse sentido, as possibilidades para a formação docente continuada, que a nossa pesquisa evidencia, pretendem subsidiar e incentivar avanços - contemporaneamente necessários e ao alcance dos professores e dos cursos de formação docente inicial e contínua - na ação educativa como prática social comprometida com ganhos efetivos no ensino e aprendizagem.

\footnotetext{
' O projeto ACOT (Apple ClassroomsofTomorrow) foi pioneiro na introdução da informática em escolas
} 
e-Mosaicos - Revista Multidisciplinar de Ensino, Pesquisa, Extensão e Cultura do Instituto de Aplicação Fernando Rodrigues da Silveira (CAp-UERJ)

V. 4 - N. 7 - JUNHO 2015 - ISSN: 2316-9303

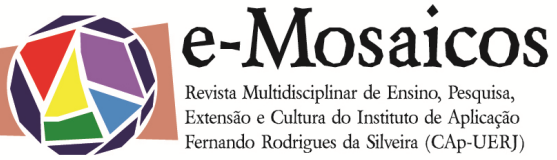

Americanas. 0 projeto destaca o trabalho colaborativo realizado entre professor e aluno e a necessidade do aperfeiçoamento profissional na escola.

ii O Enlaces-Brasil é um programa de desenvolvimento profissional destinado a professores e alunos do Ensino Fundamental e Médio que tem como objetivo criar a apoiar comunidades colaborativas que integram ambientes virtuais de aprendizagem e que propiciem a construção do conhecimento.

iii Smartphone: um telefone celular que pode executar muitas funções de um computador e um sistema operacional capaz de executar determinados aplicativos.

iv Tablet: é um dispositivo pessoal em formato de prancheta que pode ser usado para acesso à Internet, organização pessoal, visualização de fotos, vídeos, leitura de livros, jornais e revistas e para entretenimento

${ }^{\vee}$ Atividades presenciais são aquelas realizadas coma reunião dos sujeitos num mesmo espaço (laboratório, sala de aula) e ao mesmo tempo; já as atividades à distância não exigem que os sujeitos estejam, simultaneamente, num mesmo ambiente.

viskypecasté um serviço oferecido gratuitamente que permite conversações ao vivo entre grupos de até 100 pessoas, em qualquer lugar do mundo. Os Skypecasts eram moderados por um 'anfitrião' que tinha a capacidade de administrar o grupo: ele podia tirar a voz de um participante, eliminá-lo da conversa. Hoje utilizamos o termo Skype.

viino

endereço

http://www.englishmedialab.com/higherlevels.html

há planos de aula subdivididos em: elementary, preintermediate e post beginners (básico, préintermediário e pós-iniciante).

viii Nesse caso, há a preocupação de base técnica de disponibilizar microfones e caixas de som ligados aos computadores.

${ }^{i x}$ Chat é serviço de conversação em tempo real pela rede mundial de computadores.

x O sistema de rubricas fornece um conjunto de guias variáveis (nota ou percentagem) que permite avaliar o trabalho. O professor pode elaborar a avaliação utilizando a ferramenta disponível em http://rubistar.4teachers.org/index.php.

xi Em

http://claweb.cla.unipd.it/home/mcanapero/lectures .htm, por exemplo, se acessa a textos e exercícios de temas como tecnologia, ciências biológicas, astronomia e da área ambiental. Outro exemplo está em http://www.voanews.com que disponibiliza vídeos, áudios e reportagens. Já em http://www.discoveryeducation.com/free-

puzzlemaker/ é possível criar exercícios online como caça-palavras e cruzadinhas.

xii De modo simplificado, entendemos por alfabetização tecnológica o domínio técnico e pedagógico que o professor apresenta para lidar com as tecnologias e aplicá-las criticamente no seu fazer pedagógico, como a aplicação dos recursos de informática para manuseio do computador e navegação na Internet.

xiii $\mathrm{O}$ fórum de discussão consiste num espaço do ambiente virtual de aprendizagem, com acesso disponibilizado via Internet, onde os participantes deixam mensagens escritas em torno de tema proposto.

xiv Todos os depoimentos e avaliações, originalmente escritos na Língua Inglesa, foram por nós traduzidos para a Língua Portuguesa.

${ }^{x v}$ Que impacto essas ferramentas de áudio podem provocar nas suas aulas?

xvi Chamamos de recursos midiáticos os instrumentos da mídia que possibilitam a comunicação.

xvii $O$ conceito de interação focaliza o comportamento e relacionamento das pessoas, envolvendo dois ou mais atores humanos, levando em conta a intersubjetividade. Difere de interatividade, que se refere às características dos sistemas tecnológicos.

xviii Forum: ferramenta que possibilita uma discussão colaborativa sobre um tema, em que as pessoas podem inserir seus comentários sobre a temática. É um debate coletivo em rede.

\section{REFERÊNCIAS BIBLIOGRÁFICAS}

ACESSO. Desliguem seus monitores: professores do projeto Enlaces contam suas experiências com tecnologia na sala de aula. São Paulo: Secretaria de Estado da Educação, n.16, out. 2002.

ALMEIDA, M. E. B. de. Proinfo: informática $e$ formação de professores. v. 2. Secretaria de Educação a Distância. Brasília: Ministério da Educação, Seed, 2000. 191p.

BARDIN, L. Análise de conteúdo. Lisboa: Edições 70, 1977.

BARRETO, R. G. et al. As tecnologias da informação e da comunicação na formação de professores. RevistaBrasileira de Educação. São Paulo. v. 11, n. 31, p. 3142, 2006. 
BEATTY, K. Teaching and Researching computer-assisted language learning. London: Pearson Education, 2003.

BOHN, H. I. Maneiras inovadoras de ensinar e aprender: a necessidade de des(re)construção de conceitos. In: LEFFA, V. J. O professor de línguas estrangeiras: construindo a profissão. 2 ed. Pelotas: Educat, 2006. p. 123-131.

BRASIL. Ministério da Educação e do Desporto. Diretrizes curriculares para 0 ensino médio. Brasília, DF: MEC, 2008. Disponível em: $<$ http://www.educadores.diaadia.pr.gov.br /arquivos/File/diretrizes/dce_lem.pdf> Acesso em: 16 de junho de 2015. BRITO, G. S; PURIFICAÇÃO, I. Educação e novas tecnologias: um re-pensar. Curitiba: IBPEX, 2006. 120p.

CAMPOS, F. C. A.; SANTORO, F. M.; BORGES, M. R. S.; SANTOS, N. Cooperação e aprendizagem on-line. Rio de Janeiro: DP\&A, 2003.

CELANI, M. A. A. Ensino de línguas estrangeiras: ocupação ou profissão. In: LEFFA, V. J. (org.) O professor de línguas estrangeiras: construindo a profissão. 2. ed., Pelotas: EDUCAT, 2006. p. 23-43.

HARASSIM, L. et al. Redes de aprendizagem: um guia para ensino e aprendizagem on-line.São Paulo: Senac, 2005. 416p.

KHALIL, S. M.From resistance to acceptance and use of technology in academia.Open Praxis, v. 5 issue2, AprilJune 2013, p. 151-163. Disponível em: $<$ http://openpraxis.org/index.php/OpenPr axis/article/view/5/33> Acesso em 16 de junho 2015.

KENSKI, V. M. Tecnologias e ensino presencial e a distância.3 ed. Campinas: Papirus, 2006. 157p.
MASETTO, M. T. Mediação pedagógica e o uso da tecnologia. In: MORAN, J. M.; MASETTO, M. T.; BEHRENS, M. A. Novas tecnologias e mediação pedagógica. 12 ed. Campinas: Papirus, 2006. p. 133-173.

MELO, L. C. P.; SILVA, C. G. Ciência, tecnologia e inovação: desafio para a sociedade brasileira - livro verde. Brasília. 2001.

PAIVA, V. L. M. O. A www e o ensino de inglês. Revista Brasileira de Linguística Aplicada.v.1, n.1, p. 93-116, 2001. Disponível em: <http://www.veramenezes.com/www.htm $>$ acesso em 16 de junho de 2015.

PIMENTA, S. G.; ANASTASIOU, L. G. C. Docência no ensino superior. São Paulo: Cortez, 2002. 279p.

PORTO, T. M. E. As tecnologias de comunicação e informação na escola; relações possíveis... relações construídas. Revista Brasileira de Educação.v.11, n.31, p. 43-57, 2006.

PRETTO, N.; PINTO, C. C. Tecnologias e novas educações. Revista Brasileira de Educação. São Paulo. v.11, n.31, p.19-30, 2006.

SANDHOLTZ, J. H.; RINGSTAFF, C.; DWYER, D. C. Ensinando com tecnologia: criando salas de aula centradas nos alunos. Porto Alegre: Artes Médicas, 1997. $196 \mathrm{p}$.

SCHÖN, D. Educating the reflective practitioner. San Francisco: Jossey-Bass, 1988.

SOUZA, S. A. F. Internet \& Ensino de Línguas. Manaus, 2000. Composto em Agaramond e publicado em PDF no Corel Draw 9.0. 76 p. 
e-Mosaicos - Revista Multidisciplinar de Ensino, Pesquisa, Extensão e Cultura do Instituto de Aplicação Fernando Rodrigues da Silveira (CAp-UERJ)

WANG, W. The applicability of the internet in EFL teaching in China. In: Sino-US English Teaching. USA. v.2, n.4, Abril 2005.

WARSCHAUER, M.; SHETZER, H.; MELONI, $C$. Internet for english teaching. Alexandria: VA: TESOL, 2000. Disponível em: $\quad<$ http://www.teslej.org/wordpress/issues/volume5/ej17/ej1 7r17/?wscr> acesso em 16 de junho 2015.

WEASENFORTH, D. Internet for English teaching. In: TESL - EJ - Teaching English as a second or foreign language. v. 5, n.1, Abril, 2001. 